\title{
DIPLOIDY IN THE TETRAPOLAR HETEROTHALLIC BASIDIOMYCETE SCHIZOPHYLLUM COMMUNE*
}

\author{
Y. PARAG and BILHA NACHMAN \\ Deportment of Botony, The Hebrew University, Jerusalem, Isroel
}

IN Schizophyllum commune, heterothallism, or self-incompatibility, is controlled by two genetic factors, $A$ and $B$. Matings between two strains heteroallelic for both $A$ and $B$ result in the establishment of dikaryons with two haploid nuclei per cell. Matings that are homoallelic for one factor, $A$ or $B$, yield common- $A$ or common- $B$ heterokaryons, respectively. The diploid stage is normally confined to the basidium, borne on the dikaryon. Evidence is presented here, however, for the existence of a permanent diploid stage resulting from a common- $B$ mating (e.g. $A_{41} B_{42} \times A_{42} B_{42}$ ).

Previous studies (Parag, I964, I965) gave the following information. (a) The cells in the common- $B$-mycelia-many of them carrying pseudoclamps-are usually uninucleate, except the apical ones. (b) The apical cells are usually either binucleate or uninucleate. (c) Side branches, those originating from pseudoclamps included, start their development from uninucleate cells. From all this it is apparent that small fragments of mycelium should yield mycelia predominantly homokaryotic if the original mycelium be heterokaryotic. Mycelia of the common- $B$ "heterokaryon" het-4 (Parag, I965) ( $A_{42} B_{42}$ arg-6: $A_{4}$ I $B_{42}$ ad-2 nic-3) were macerated (in M.S.E. "ATO-MIX", 12,000 r.p.m.) and the macerate plated on complete medium in different concentrations. In one series of tests the concentration was adjusted for the expected yield of $c a .750$ and 150 viable fragments per plate, on which the homokaryotic segregants should be distinguished by the difference in their gross morphology. Among ca. 9000 mycelia plated by this method no homokaryon could be recognised. In a second series of tests ca. 650 viable fragments were sown, 30-40 per plate to facilitate careful microscopic examination. No homokaryotic hyphæ (lacking pseudoclamps) were detected under the microscope. From 20 of these young mycelia, viable hyphal tips were isolated. The mycelium that developed from one of these isolates yielded a sector lackings pseudoclamps. The genotype of this homokaryon was found to be $A_{4}$ I $B_{42} \mathrm{arg}^{+} \mathrm{ad}^{+} \mathrm{nic}^{+}$. It apparently resulted from somatic recombination in the common- $B$ mycelium. These results confirmed the previously observed extreme stability of this common- $B$ mycelium (Parag, 1965).

In a previous study (Parag, 1965) one mycelium with homokaryotic morphology was obtained. Its phenotype was $\mathrm{A}_{41} \mathrm{~B}_{42} \mathrm{arg}^{+} \mathrm{ad}^{+} \mathrm{nic}^{+}$. Small samples (9-22 viable spores) were taken from three fruiting bodies from two crosses involving this homokaryon. In all three fruiting bodies, there was a segregation of $A_{41}$ and $B_{42}$ (but no $A_{42}$ ), and, in two of them, there was a segregation of all the three biochemical markers. From this it can be concluded that this "homokaryon" was either $(a)$ an aneuploid disomic for three linkage groups: $\frac{A_{41}}{B_{4}} \frac{B_{4}}{+} \frac{a d-2}{+} \frac{n i c-3}{+} \frac{+}{a r g-6}$ or $(b)$ a recombinant

* Adapted in part from a thesis submitted by the junior author to the Department of Botany, The Hebrew University, in partial fulfilment of the requirements for the degree of Master of Science, 1964 . 
homoallelic for $A$ : $\frac{A_{4} \mathrm{r}}{A_{41} \mathrm{r}} \frac{B_{42}}{B_{42}} \frac{a d-2}{+} \frac{n i c-3}{+} \frac{+}{\arg -6}$. Either explanation requires a diploid nucleus from which such genotypes could be derived.

It has been previously observed (Buller, I931; Papazian, 1950; Raper, 1953; Ellingboe and Raper, I962; Parag, 1965) that on mating a heterokaryon (or a dikaryon) with a homokaryon compatible with one of the

TABLE I

Analysis of progeny from a cross between the suspected diploid, " het-4", and a homokaryon: $\frac{\mathrm{A}_{42}}{\mathrm{~A}_{4} \mathrm{I}} \frac{\mathrm{B}_{42}}{\mathrm{~B}_{42}} \frac{\arg -6}{+} \frac{t}{\mathrm{ad}-2} \frac{t}{\text { nic-3 }} \times \underline{\mathrm{A}}_{4} \mathrm{I}$ pab $\underline{\mathrm{B}_{5} \mathrm{I}}$

\begin{tabular}{|c|c|c|c|c|c|c|c|}
\hline \multirow{2}{*}{$\begin{array}{l}\text { Biochemical } \\
\text { markers }\end{array}$} & \multicolumn{7}{|c|}{ Mating types } \\
\hline & $A_{42} B_{42}$ & $A_{41} B_{42}$ & $A_{42} B_{51}$ & $A_{4} \mathrm{I} B_{5} \mathrm{I}$ & $A \times B 42$ & $A \times B_{5}$ & Total \\
\hline $\begin{array}{l}\text { arg ad nic pab } \\
\text { arg ad nic + } \\
\text { arg ad + pab } \\
\text { arg + nic pab } \\
+ \text { ad nic pab } \\
\text { arg ad + + } \\
\text { arg + nic + } \\
\text { arg + + pab } \\
+ \text { ad nic + } \\
+ \text { ad + pab } \\
++ \text { nic pab } \\
\text { arg + + + } \\
+a d++ \\
++ \text { nic + } \\
+++ \text { pab } \\
+++++\end{array}$ & $\begin{array}{l}\ldots \\
\ldots \\
\ldots \\
\ldots \\
\ldots \\
\cdots \\
2^{* *} \\
\ldots \\
I^{* *} \\
\ldots \\
\ldots \\
3 \\
6^{* *} \\
2^{* *} \\
\ldots \\
5\end{array}$ & $\begin{array}{l}\cdots \\
2^{*} \\
\ldots \\
2^{*} \\
5^{* * *} \\
\ldots \\
1^{* *} \\
\ldots \\
\ldots \\
4^{* * *} \\
\ldots \\
\ldots \\
2^{* * *} \\
1 * * \\
3 \\
3^{* * *}\end{array}$ & $\begin{array}{c}\cdots \\
2^{*} \\
\ldots \\
\cdots \\
\cdots \\
1^{*} \\
1^{*} \\
2^{*} \\
\ldots \\
\cdots \\
5 \\
6^{*} \\
2^{*} \\
\cdots \\
3\end{array}$ & $\begin{array}{l}I^{*} \\
I^{*} \\
I^{*} \\
\ldots \\
3^{* * *} \\
\cdots \\
3^{*} \\
1 \\
2^{* * *} \\
7^{* * *} \\
2^{* * *} \\
2^{*} \\
2^{* * *} \\
2^{* * *} \\
6 \\
I^{* * *}\end{array}$ & $\begin{array}{l}\ldots \\
\ldots \\
\ldots \\
\ldots \\
\cdots \\
\ldots \\
\ldots \\
\ldots \\
\ldots \\
\ldots \\
\cdots \\
\ldots \\
\text { I** } \\
\ldots \\
\cdots \\
\text { I }\end{array}$ & $\begin{array}{l}\cdots \\
\cdots \\
\cdots \\
\cdots \\
\cdots \\
\cdots \\
\cdots \\
\cdots \\
\cdots \\
\cdots \\
\cdots \\
\cdots \\
2^{*} \\
\cdots \\
\text { I } \\
\text { I }\end{array}$ & $\begin{array}{r}1 \\
5 \\
1 \\
2 \\
8 \\
1 \\
7 \\
1 \\
5 \\
11 \\
2 \\
10 \\
19 \\
7 \\
10 \\
14 \\
\end{array}$ \\
\hline Total $\dagger$. & 19 & 23 & 22 & 34 & 2 & 4 & 104 \\
\hline
\end{tabular}

x Recombinant $A$ factor.

* Segregants carrying markers from all three genomes involved in the cross-28 altogether.

** Segregants carrying markers from the two genomes of " het- 4 " - I 3 altogether.

*** Segregants carrying markers from the component $A_{4}$ " $B_{42}$ of "het-4"-34 altogether.

$\dagger$ Total exceptional segregants: 75 .

components of the heterokaryon (or dikaryon), the homokaryon becomes dikaryotised; e.g.

$$
\underset{\text { heterokaryon }}{\left(A_{41} B_{42}: A_{42} B_{42}\right)} \underset{\text { homokaryon }}{A_{41}} B_{5} B_{\text {I }} \rightarrow\left(A_{42} B_{42}+A_{41} B_{51}\right) .
$$

The derived dikaryon thus includes the nucleus of the homokaryon and one of the nuclear types of the heterokaryon. Several crosses of this type were made involving " het- 4 " as one partner. Segregants in all of these crosses were tested from single fruiting bodies emerging from the derived dikaryons. The frequency of germination of the spores and the viability of the germinating spores were both very low. The samples, except one, were consequently small. In the largest sample, 350 germinating spores were isolated, but only 120 were viable-and of these I04 were fully analysed (table 1). The 
progeny of this fruiting body differed from expectation in a heterokaryon $x$ homokaryon cross by three criteria. (a) In addition to the markers of the homokaryon, markers of both components of the heterokaryon were present. (b) Many single-spore segregants carried markers of both components of " het-4" and even markers of all three genomes involved in the cross. (c) The most significant result is as follows. Since pab is located between the two genes constituting the $A$ factor (Raper, Baxter and Ellingboe, I96o), we have in this cross three alternative $A^{\prime}$ 's: $A_{42} A_{4}$ r,$A_{4}$ I $p a b$. All three $A$ 's were found in the progeny of this single fruiting body. In the three other crosses, 17,26 and $3^{8}$ viable segregants were tested and the results were similar to the above. In addition, in two of these crosses, I I of 26 and 8 of $3^{8}$ segregants had the morphology and mating reactions of common- $A$ heterokaryons, and they were very probably disomic (Raper and Oettinger, 1960).

It has already been observed (Parag, I962) that rare somatic recombinants may be present in dikaryons (and may be assumed in heterokaryons). It has been further observed that somatic recombinants resulting from dikaryon $\times$ homokaryon matings (and presumably from heterokaryon $\times$ homokaryon matings) may carry markers from the three genomes involved in the mating (Ellingboe and Raper, 1962). There is also no clear evidence that single fruiting bodies arise solely from single hyphæ, thus the possibility of chimeric fruiting bodies should not be overlooked. Taking all this into consideration, however, we still cannot explain the three following points on the assumption that "het- 4 " is a heterokaryon. (a) The finding of aneuploid (or diploid) nuclei in the " homokaryotic" vegetative segregants. (b) The finding of all three alternate $A$ 's and markers of all three genomes involved in the cross in a single fruiting body. (c) The extreme stability of the common- $B$ mycelium composed mainly of uninucleate cells.

All our results agree very well with the hypothesis that "het-4" is actually a permanent diploid mycelium and rule out any other conceivable hypothesis.

It is of pertinence here that " het- 4 " carries pseudoclamps regularly (i.e. every septum has its adjacent pseudoclamp) and that Schvif (1965) found that there are common- $B$ heterokaryons carrying no pseudoclamps at all. From these heterokaryons she could select mycelia regularly carrying pseudoclamps. The latter mycelia were very stable and appeared to be similar to "het-4". It is therefore suggested that regular appearance of pseudoclamps adjacent to every septum and on every hypha is characteristic of common- $B$ diploids. Common- $B$ diploids may thus be morphologically distinguished from dikaryons and heterokaryons. If this morphological difference is confirmed as a certain criterion for common- $B$ diploidy it may facilitate the use of diploid mycelia for genetic studies.

Our results present evidence for permanent diploidy in vegetative mycelia of Hymenomycetes. This is in contrast to the previously held opinion that diploid nuclei are ephemeral and confined to the basidia, and that diploid vegetative stage is non-existent. The recent reports about diploids in Coprinus (Casselton, 1965; Prud'homme, 1965), using common- $A$ matings and dikaryon-homokaryon matings, support our conclusions. The significance of diploidy in relation to the mechanism of self-incompatibility and to life cycles of Basidiomycetes, and for genetic investigation into the interactions between genes in diploids as compared to dikaryons (or heterokaryons) will be discussed in detail elsewhere. 


\section{SUMMARY}

In Schizophyllum commune, a common- $B$ mycelium, resulting from the mating $A_{42} B_{42}$ arg- $6 \times A_{41}{ }^{1} B_{42}$ ad-2 nic-3, was found to be a permanent diploid rather than a heterokaryon. The evidence for the diploidy is threefold. (a) The mycelium which carries pseudoclamps typical of common- $B$ mycelia is very stable and does not yield vegetative homokaryotic segregants as expected if it were a heterokaryon. (b) Only two vegetative segregants with homokaryotic morphology were found: one was a somatic recombinant and the other, an aneuploid or diploid. (c) A cross between the diploid mycelium and a homokaryon (haploid) gave the segregation expected from a diploid $\times$ haploid cross. Diploid nuclei in Hymenomycetes are therefore not confined to the basidia as was assumed thus far.

Acknowledgments.-Our sincere thanks are due to Prof. J. R. Raper for critically reading the manuscript. We are indebted to Mr I. Baldinger for technical assistance.

\section{REFERENCES}

BULLER, A. H. R. I93I. Researches on Fungi. IV. Longman Green \& Co., London. GASSELton, L. A. 1965. The production and behaviour of diploids of Coprinus lagopus. Genet. Res. Camb., 6, 190-208.

ELLINGBOE, A. H., AND RAPER, J. R. I962. Somatic recombination in Schizophyllum commune. Genetics, 47, 85-98.

Papazian, H. P. I950. Physiology of the incompatibility factors in Schizophyllum commune. Bot. Gaz., I12, I43-I63.

PARAG, Y. 1962. Studies on somatic recombination in dikaryons of Schizophyllum commune. Heredity, $17,305-318$.

PARAG, Y. I964. Diploid mycelia resulting from common-B matings of Schizophyllum. Abst. Intern. Botan. Congr. Ioth, Edinburgh, pp. 44I-442.

PARAG, Y. 1965. Common-B heterokaryosis and fruiting in Schizophyllum commune. Mycologia, 57, 543-561.

PRUD'HOMME, N. I965. Somatic recombination in Coprinus radiatus. In Incompatibility in Fungi, K. Esser and J. R. Raper, Eds. Springer-Verlag, Heidelberg. In press.

RAPER, J. R. 1953. Tetrapolar sexuality. Quart. Rev. Biol., 28, 233-259.

RAPER, J. R., BAXTER, M. G., AND ELLINGBOE, A. H. 1960. The genetic structure of the incompatibility factors of Schizophyllum commune: The $A$-factor. Proc. Natl. Acad. Sci. U.S.A., 46, 833-842.

RAPER, J. R., AND OETTINGER, M. T. 1962. Anomalous segregation of incompatibility factors in Schizophyllum commune, Revta. Biol. Lisb., 3, 205-221.

schvir, D. 1965. Common-B heterokaryons in Schizophyllum commune. M.Sc. Thesis, The Hebrew University, Jerusalem, Israel (in Hebrew).

\section{A CARABID BEETLE WITH ONLY EIGHT CHROMOSOMES}

\section{J. WAHRMAN}

Laboratory of Genetics, The Hebrew University, Jerusalem, Israel

Regently a diploid chromosome number of eight was found in a chrysomelid beetle (Virkki and Purcell, 1965). This number, which had not been recorded previously, is the lowest known among about a thousand 